\title{
Editorial:
}

\section{Modelling and evaluating the sustainability of smart solutions}

\author{
Lorenz M. Hilty, Bernard Aebischer, and Andrea E. Rizzoli \\ hilty@ifi.uzh.ch
}

\begin{abstract}
Smart technologies provide diverse and promising opportunities for reducing energy demand and greenhouse gas emissions; they are increasingly expected to shift modern societies' patterns of production and consumption towards sustainability. However, the existence of a theoretical potential does not imply that every smart solution (application of a smart technology) will actually contribute to sustainability. Policymakers therefore need methodologies for evaluating the sustainability of smart solutions. This paper gives an overview of the current discussion in the field and the emerging methodological challenges. The challenges of assessing the direct impact of the ICT components and infrastructures are special cases of known issues in life cycle assessment methodology. The challenges of assessing indirect impacts are inherently interdisciplinary and call for integrated modelling approaches. The last two sections provide an overview of the papers assembled in this thematic issue that treat specific cases and general principles of modelling and evaluating the sustainability of smart solutions.
\end{abstract}

\section{Introduction}

Making the world smarter by adding computing, sensing, and networking capacity to objects and infrastructures is a vision that emerged more than a decade ago from the field of ubiquitous computing. "Smart things" were envisioned with the ability to explore their environments and to communicate with each other, thus "enabling innovative products and totally new services to be developed" (Mattern, 2004, 155). "Smart environments" were designed, "able to acquire and apply knowledge about [... their] inhabitants in order to improve their experience in that environment" (Cook and Das, 2007, 54).

"Smartness" became a metaphor for the integration of Information and Communication Technology (ICT) in formerly passive products and infrastructures to make them more responsive and to give software more control over real-world processes. While this metaphor has been turned into daily reality in some cases - such as the smart label ${ }^{1}$ and the smartphone - others are still far from everyday practice, such as smart grids (as defined in EFC, 2003), smart cities (as defined in Caragliu et al., 2009, see also Kramers et al., in this issue), or smart sensor networks (as described in Weber, 2009).

1 Labels on product packaging or the product itself containing an RFID (Radio-Frequency IDentification) chip. The advantages and disadvantages of their application have been discussed broadly in the last decade, e.g. Wäger et al. (2005); Oertel et al. (2005).

This Accepted Author Manuscript is copyrighted and published by Elsevier. The final publication is available at Elsevier via http://www.sciencedirect.com/science/article/pii/S1364815214001029

Suggested citation: Hilty, L.M., Aebischer, B., Rizzoli, A.E. 2014. Modeling and Evaluating the Sustainablity of Smart Solutions (Editorial), Environmental Modelling and Software 56, 1-5 
Although every application of smart technologies is designed and deployed to solve a specific problem, there is a discussion about the general trend towards "smartness" (or "smart everything", Koomey et al., 2013) and its potential to solve the predominant problem of modern societies: shifting from unsustainable towards sustainable patterns of production and consumption. Laitner subsumes smart buildings, smart appliances, and smart grids under the generic concept of "smart energy solutions" (Laitner, 2010, 692).

Seminal studies have pointed out the potential of smart technologies to contribute to the energy productivity of the US economy (Laitner et al., 2001, 2009), the abatement of greenhouse gas (GHG) emissions (GeSI, 2008, 2012) at the national and global scales, and strategies of "green growth" (Mickoleit, 2010), which the OECD defines as "fostering economic growth and development, while ensuring that natural assets continue to provide the resources and environmental services on which our well-being relies" (OECD, 2011, 4).

Although there is evidence from these studies that ICT has a high potential to reduce the energy and material flows through today's economies overall - and thus to mitigate the pressure on ecosystems and slow down climate change - there is no guarantee that this will actually happen. Every specific smart solution may or may not be sustainable, depending on the size of its own environmental footprint and on the actual reduction of environmental impact it brings about by improving other processes. This may differ from the potential reduction because the theoretical potentials may materialize only under specific conditions or may be compensated by other processes that are used more or enabled at all as a consequence of the specific smart solution. Assessing the sustainability of smart solutions usually requires accounting for the dynamics of complex systems and using multiple criteria in the methods of evaluation.

We hope that this thematic issue will contribute to the development of sound approaches to assessing the sustainability of smart solutions. The fundamental methodological challenges of such assessments will be addressed in more detail in Section 2 of this paper. Sections 3 and 4 will provide an overview of the papers assembled in this issue.

The idea for this thematic issue emerged at the first International Conference on Information and Communication Technologies for Sustainability (ICT4S), held in 2013 in Zurich, where the self-critical question "How do we know if this solution is really sustainable?" was addressed in many contributions (Hilty et al., 2013). Some of the papers gathered in this issue are expanded versions of papers presented at ICT4S, others were submitted in response to the open call for papers.

\section{Smart solutions - sustainable solutions?}

In 2008, the Global e-Sustainability Initiative (GeSI), an association of over 30 leading ICT companies, published the "SMART 2020" study. This report estimated that the GHG emissions from the ICT sector will represent $3 \%$ of total global emissions by 2020 , but that ICT will help other industries and consumers avoid $15 \%$ of predicted total global emissions (or five times its own footprint) by enabling "smart motor systems," "smart logistics," "smart

This Accepted Author Manuscript is copyrighted and published by Elsevier. The final publication is available at Elsevier via http://www.sciencedirect.com/science/article/pii/S1364815214001029

Suggested citation: Hilty, L.M., Aebischer, B., Rizzoli, A.E. 2014. Modeling and Evaluating the Sustainablity of Smart Solutions (Editorial), Environmental Modelling and Software 56, 1-5 
buildings," "smart grids," and "dematerialization"” (GeSI, 2008). A recent update of the study titled "GeSI SMARTer 2020" extended this claim by estimating the greenhouse gas abatement potential of ICT to be "seven times the size of the ICT sector's direct emissions" (GeSI, 2012, 19).

We will take these studies as examples for discussing methodological challenges. Their focus on GHG emissions will not limit the scope of the discussion, as the arguments can be generalized to other aspects of environmental sustainability. Neither should our remarks be understood as specific criticism of the GeSI studies; all studies in this field face essentially the same challenges (see Erdmann and Hilty, 2010, for a review of studies on ICT impacts on GHG emissions).

Like other studies in this field, the GeSI studies basically estimate two types of impacts of ICT:

- The direct impact throughout the life cycle of ICT components, for example, the emissions caused by producing them and supplying them with power;

- The indirect impact of ICT by providing functions, for example, the emissions avoided by using a smart solution to increase the energy efficiency of a particular production or consumption process (also called enabling impact).

These two impacts are then compared to find the net impact of ICT, which is the indirect impact (avoided emissions) minus the direct impact (ICT's own emissions). Proposals for more differentiated conceptual frameworks of ICT effects on sustainability are found in the literature (see Hilty and Lohmann, 2013, for a bibliography). For the following discussion, it will be sufficient to note that the direct and indirect impacts are fundamentally different in nature:

- The direct impact is real because it occurs when ICT is produced, used, and disposed of, and the emissions caused by these activities can be measured (at least in principle, not always in practice);

- The indirect impact is hypothetical because is it occurs when an activity is avoided that would otherwise have taken place and caused emissions; as a matter of principle, the emissions of an avoided activity cannot be measured - only modeled.

For example, to ascertain the amount of emissions saved by videoconferencing equipment provided for virtual meetings, we could determine the direct impact by measuring the emissions arising from the production of the screens and cameras, the routers and switches etc. needed for the videoconference, and the emissions from providing them with electricity during use. To determine the indirect impact, however, we would have to know what would have happened if the equipment had not been available: Would people have traveled to the meeting by car or by public transport, by ship or by plane? Or would they have used the

2 Dematerialization is defined in this context as replacing physical objects and processes with virtual alternatives, such as using electronic documents instead of printed ones or videoconferencing instead of traveling to meetings.

This Accepted Author Manuscript is copyrighted and published by Elsevier. The final publication is available at Elsevier via http://www.sciencedirect.com/science/article/pii/S1364815214001029

Suggested citation: Hilty, L.M., Aebischer, B., Rizzoli, A.E. 2014. Modeling and Evaluating the Sustainablity of Smart Solutions (Editorial), Environmental Modelling and Software 56, 1-5 
telephone instead, or had no meeting at all? Depending on the answer, the indirect impact could vary between zero and a multiple of the direct impact. ${ }^{3}$

The fundamental difference results in distinct methodological challenges for determining direct and indirect impacts, which will be discussed in the following.

For the direct impact, the challenges are those known in LCA methodology, in particular:

- Defining the system boundary, for example, whether or not end-user devices should be included in the system under study when assessing the energy consumed by the Internet. ${ }^{4}$

- Collecting life-cycle inventory data and judging its quality, for example, how to deal with data referring to older components in a world of rapid change; how to deal with average values for phenomena with high variance.

- Dealing with allocation issues, for example, how much of the life-cycle-wide emissions of an Internet router are to be allocated to one specific use.

When assessing indirect impact, one is also faced with these challenges (because the avoided activities must be treated with an LCA approach as well), plus some more fundamental ones, which are more difficult to handle:

- Defining the baseline, for example, the amount of passenger traffic that would be caused by people meeting for discussions if there were no further progress in technologies used for virtual meetings?

- Differentiating between potential and actual impact, for example, the extent to which smart meters with the potential to support energy saving in private households will actually change consumer behavior.

- Anticipating systemic effects, for example, the extent to which smarter traffic management, if successful in avoiding congestion, will attract more commuters to using private transportation, leading to additional emissions and new congestion?

We will briefly discuss the three fundamental challenges in the following subsections.

\subsection{Defining the baseline}

The challenge of defining the baseline is inherent to assessing indirect impacts because the concept of indirect impact is inevitably based on the concept of avoided burden. The baseline is a quantitative description of what is assumed to happen without the technological solution under study and can have various forms, from a simple number to the results of calculating a complex scenario (often called "business-as-usual" or "BAU" scenario) with a quantitative model.

3 See Coroama et al. (2012) for a study in which a survey was used to find out what users would have done if no videoconferencing had been available.

4 See Coroama et al. (2013) for this specific example and Coroama and Hilty (2014) for a review of assessments of Internet energy intensity.

This Accepted Author Manuscript is copyrighted and published by Elsevier. The final publication is available at Elsevier via http://www.sciencedirect.com/science/article/pii/S1364815214001029

Suggested citation: Hilty, L.M., Aebischer, B., Rizzoli, A.E. 2014. Modeling and Evaluating the Sustainablity of Smart Solutions (Editorial), Environmental Modelling and Software 56, 1-5 
Defining the baseline is critical, in particular if future projections of complex socioeconomic developments are involved. If we assume, for example, that fossil energy will remain cheap and transport will continue to grow, the potential to avoid emissions through videoconferencing, smart logistics, and virtual goods will be much higher than in a world of high energy prices. In other words, the avoided burden can always be increased by defining a pessimistic baseline. The baseline may contain implicit assumptions having a large effect on the result, e.g., in a world of carbon-based electricity, a complex energy-saving light source has a much higher potential to avoid emissions than in a world of a cleaner electricity mix (Welz et al., 2010).

A researcher choosing an inherently unsustainable baseline scenario acts like a doctor telling a patient that the medication will be most effective if his illness is most serious. This may be true, but not really helpful to the patient.

From a strictly empirical point of view, an indirect impact could only be determined in a controlled experiment comparing two cases that differ in the application of the technology under study, while keeping all other conditions equal. The case that does not receive the "treatment" by the technology corresponds to the baseline. However, since it is usually neither feasible nor desirable to conduct controlled experiments with large human populations, researchers use models instead. All published estimates of indirect effects are therefore, either explicitly or implicitly, model-based.

How has the problem of defining the baseline has been dealt with in studies on ICT effect on sustainability so far?

The GeSI study (GeSI, 2012) uses a BAU scenario prepared by the International Energy Agency (IEA) which quantifies the expected global increase in GHG emissions. Because it is unclear on which implicit assumptions about future ICT the IEA scenario is based, comparing the BAU and the "smart" scenario seems problematic. The authors admit this problem by stating: "The BAU case contains some intrinsic improvement in technology based on historic trends. This may overlap with some of the abatement potential identified in this report." (GeSI, 2012, 19)

The study of the American Council for an Energy-Efficient Economy (ACEEE), published by Laitner et al. (2009), used a method called "freezing" to create the baseline: "The ACEEE study first created a 'frozen efficiency' scenario to more clearly see how the next 2 decades might look if the United States were to rely on today's technologies and freeze its performance even as the country tried to grow the economy out to 2030." One of the study's conclusions was that "new investments in the semiconductor industry could result in a net $27 \%$ total energy savings by 2030." (Laitner 2010, 693)

The same technique had already been used in one of the earlier studies on the impact of ICT on sustainability, commissioned by the Institute for Prospective Technological Studies (IPTS) in 2002 and published by Erdmann et al. (2004) and Hilty et al. (2006a). The goal of the study was to explore the impacts of ICT on environmental sustainability in the European Union. Here, the baseline was defined by "freezing" the further development and diffusion of ICT at the level of the year 2000. Several socioeconomic developments from 2000 to 2020 were simulated, each of them in one variant with "frozen" ICT and one with the projected ICT development (for details see Hilty et al., 2004). One of the conclusions of this study was that ICT has a high potential to save energy if used for smarter space heating in existing buildings.

This Accepted Author Manuscript is copyrighted and published by Elsevier. The final publication is available at Elsevier via http://www.sciencedirect.com/science/article/pii/S1364815214001029

Suggested citation: Hilty, L.M., Aebischer, B., Rizzoli, A.E. 2014. Modeling and Evaluating the Sustainablity of Smart Solutions (Editorial), Environmental Modelling and Software 56, 1-5 


\subsection{Differentiating between potential and actual impacts}

The challenge of differentiating between potential and actual impacts is connected to the fact that a potential determined by a model may or may not materialize in a real-world situation.

For example, if a company provides a service to private households, making recommendations to replace household appliances by more energy-efficient ones based on identifying and monitoring the devices by a central smart meter (also called device footprinting), this application of smart metering may have a high energy-saving potential. In theory, the recommendations for replacing appliances could be independent of commercial interests and based on full LCA to provide an optimal solution. In practice, however, various reasons may be involved in narrowing the focus to use-phase electricity only: LCA data is not available, customers like buying new appliances, or the company providing the service is involved in selling appliances. Under these conditions, the theoretical potential may not materialize and the solution may even lead to increased energy consumption overall.

The basic problem behind this challenge is that there is no guarantee that the original goals a researcher or engineer associates with a given application of technology remain the same when this application is used in practice; as a consequence of this "goal displacement" (Hilty et al., 2006b), the potential effects may not transform into actual ones.

Solving this methodological problem requires progress in understanding the incentive systems, economic mechanisms, and behaviors that drive the practical use of technology. In many cases, developing the incentive systems will be more important for realizing an intended impact than further developing the technology.

\subsection{Anticipating systemic effects}

The last challenge, anticipating systemic effects, has been widely discussed in terms of the "rebound effect." The rebound effect is a market reaction to an increase in efficiency: if a particular good or service can be produced with higher efficiency, i.e., more useful output can be generated per unit of input, the good or service may become cheaper or more convenient to use, which in turn can result in higher demand for that good or service, or for something else that becomes affordable due to the saved money or time. The rebound effect is one of the reasons why efficiency-based policies for energy saving have often failed in the past. This seems to be the case for the current EU policies as well: "The European target of cutting GHG emissions by $20 \%$ by 2020 has generated a substantial body of energy efficiency policies, but real-world observations indicate that energy savings realized in practice fall short of energy savings estimates [...] A partial explanation of this trend consists in what is called 'rebound effect' or 'take-back'. As an increased consumption of energy services following an improvement in the technical efficiency of delivering those services, the rebound effect highlights a variety of tensions between the pursuit of wellbeing and the need to remain within ecological limits." (Boulanger et al., 2013, 5)

The authors of the GeSI studies point out the relevance of the rebound effect, but declare that they could not include it in their calculations: "In general, there are several cases in which efficiency brings about a net increase in total consumption, because if a unit of consumption delivers more utility, it becomes more desirable. The calculated abatement results in this report do not include rebound effects. They are incredibly complicated and difficult to model

This Accepted Author Manuscript is copyrighted and published by Elsevier. The final publication is available at Elsevier via http://www.sciencedirect.com/science/article/pii/S1364815214001029

Suggested citation: Hilty, L.M., Aebischer, B., Rizzoli, A.E. 2014. Modeling and Evaluating the Sustainablity of Smart Solutions (Editorial), Environmental Modelling and Software 56, 1-5 
[...]. That said, rebound effects are important, and it is important for policy makers, the ICT industry, and other stakeholders to consider these effects when designing policy and discussing the environmental impact of the industry." (GeSI, 2012, 54)

Röpke and Christensen (2012) discuss the rebound effect with a focus on how ICT is integrated into everyday practices and how these technologies change our use of space and time.

There may be many systemic effects of ICT other than the market reactions to efficiency improvements called rebound effects: Long-term changes in practices of consumption and structures of production that may turn out to be positive or negative with regard to sustainability. Understanding systemic effects in this broader sense is an inherently interdisciplinary challenge, involving the issues of social practices and the interaction of technologies with ethical issues and societal risks as well (as discussed, for example, by Bohn et al., 2004; Som et al., 2009).

\subsection{The need for integrated modelling and assessment}

To conclude this section, we would like to point out that there is - unfortunately - no guarantee that a smarter solution is a more sustainable solution. Every proposed application of smart technologies has to be assessed for its implications for sustainability. There are only few examples of studies that have been devoted to assessing the sustainability of a particular smart solution so far, such as a study on intelligent transport systems (Kolosz et al., 2013). ${ }^{5}$

There is no doubt that smart technologies have an unprecedented power to transform processes, which essentially comes from the ability of these technologies to provide processes with real-time data on the flow of energy, materials, and money. "These new technologies can result in a more flexible and efficient world than has ever existed, if we use them wisely." (Koomey et al., 2013, 336).

How can we promote sustainable use of smart technologies? A major step would be a methodology of integrated assessment that would support decision-makers in assessing the sustainability of proposed smart solutions. Such a methodology should provide what Kelly et al. call a "holistic understanding" of the system processes and their interactions, which is based on models (Kelly et al., 2013). Methods of integrated assessment are already established in policy-making (Ruddy and Hilty, 2008) and should be improved to systematically capture the transformations possible, both intended and unintended, by the use of smart technologies.

Research is needed in the following areas in order to make progress towards integrated assessment of smart technologies:

5 Other examples are more limited in scope or extent: First approaches to assess the impacts of smart labels (Wäger et al., 2005) or smart textiles (Köhler et al., 2011), a case-study on smart vending machines (Hilty, 2012), and an approach to evaluate the sustainability of smart cities (Lövehagen and Bondesson, 2013).

This Accepted Author Manuscript is copyrighted and published by Elsevier. The final publication is available at Elsevier via http://www.sciencedirect.com/science/article/pii/S1364815214001029

Suggested citation: Hilty, L.M., Aebischer, B., Rizzoli, A.E. 2014. Modeling and Evaluating the Sustainablity of Smart Solutions (Editorial), Environmental Modelling and Software 56, 1-5 
1. Best practices in applying LCA methodology in the field of ICT, including defining the system boundary, dealing with uncertainty due to incomplete or outdated inventory data, and selecting allocation schemes when assessing highly multifunctional products.

2. Best practices for modelling the baseline scenario in studies that investigate the relative effect of introducing new applications of ICT for both micro- and macro-level approaches.

3. Methodologies for integrated modelling of socioeconomic systems with a focus on how ICT interacts with everyday practices, in particular the use of space and time; such models are necessary for investigating the conditions under which potential indirect impacts materialize and for predicting systemic effects. The discussion of these methodologies can build on the work on Integrated Environmental Modelling (IEM), as documented in this journal (for example, Laniak et al., 2013).

We hope that this thematic issue will contribute to closing these research gaps. Section 3 provides an overview of the papers related to direct ICT impacts in this issue, Section 4 of those related to indirect ICT impacts.

\section{Modelling and evaluating direct impacts of ICT}

One of the most pressing questions at the level of direct impacts is how the trend to cloud computing will influence the energy demand and the related GHG emissions of everyday ICT use. Williams et al. examine this question with a focus on business computing. Their model is focused on demonstrating the impact of the transition from traditional on-site computing to cloud computing and generates country-specific estimates of energy and GHG reductions.

The amount of electric power required by High Performance Computing (HPC) systems, which are the key technology for many computation-intensive applications, is increasing. Shoukourian et al. present a set of tools for collecting and evaluating data from HPC data centers that is needed for analyzing energy consumption.

In a smarter world, electronic media may replace print media to a large extent. LCA studies comparing the environmental impacts of print and electronic media face the difficulty of collecting Life Cycle Inventory (LCI) data for the ICT devices involved. Hischier et al. compare two LCA studies that were independently carried out to assess the environmental impacts of electronic versus print media. They show how differences in the results can be explained by differences in the methodological approaches used in Life Cycle Inventory (LCI) modelling.

\section{Modelling and evaluating indirect impacts of ICT}

Great hopes are placed in smart grids to allow for the integration of higher shares of distributed and renewable power generation without loss of security of supply. Niesse et al. present a process model for application-oriented research and development in ICT for power systems, including the evaluation of (distributed) control methods for smart grids with the simulation framework "mosaik".

This Accepted Author Manuscript is copyrighted and published by Elsevier. The final publication is available at Elsevier via http://www.sciencedirect.com/science/article/pii/S1364815214001029

Suggested citation: Hilty, L.M., Aebischer, B., Rizzoli, A.E. 2014. Modeling and Evaluating the Sustainablity of Smart Solutions (Editorial), Environmental Modelling and Software 56, 1-5 
The vision of the smart city is often associated with sustainable lifestyles. Kramers et al. explore the opportunities of using ICT as an enabling technology for reducing energy demand in cities. They develop an analytical framework in which a typology of ICT opportunities is combined with a typology of (energy-demanding) household functions. The framework can be used by municipal administrations and ICT companies for identifying smart solutions with a potential for sustainable development in cities.

Fernandez et al. focus on a specific infrastructure intended for smart cities: automated vacuum waste collection using air suction in a closed network of underground pipes to transport waste from the drop-off points to a central collection point. They present a model and apply constraint programming techniques to schedule the daily emptying sequences of the drop-off points in such a way that energy consumption is minimized.

Garrido-Baserba et al. use a knowledge-based Decision Support System (DSS) to include LCA-based environmental criteria in the design of wastewater treatment plants. Their results demonstrate that combined LCA and DSS implementation is suitable for assessing plant designs during the decision-making process. This example shows how ICT can indirectly contribute to sustainable solutions by improving the consideration of environmental impacts in decision-making and design processes.

Kramers proposes a set of functional requirements for sustainability-oriented decision support in the domain of travel information. Nine existing travel information systems for multimodal and public transport travel are systematically investigated to determine whether they include the proposed functionality. The result is an identification of current systems' shortcomings and a proposal for new and enhanced functionality for next-generation travel information systems.

Stiel and Teuteberg present an approach for extending LCA methodology to assess the enabling effects of Information Systems (IS). The approach complements the physical flows assessed in LCA by information flows (measured in bits). The new conceptual structure is intended to model causal relations between information flow and environmental impact as they occur in dematerialization solutions, IS-based product and service bundles, as well as the interactions between social behavior and physical systems.

With a similar aim, but a different approach, Börjesson Rivera et al. discuss the role of indirect and systemic effects on the assessment of environmental impacts of ICT solutions. They present a review of the discussion of second-order effects (which they define as indirect effects, but excluding the replacement of activities by ICT) and a differentiated categorization of the effects in rematerialization and induction effects, direct rebound effects, indirect rebound effects, economy-wide rebound effects, time rebound and space rebound effects, learning effects and scale effects, changed practices, and transformational effects. The paper discusses the basic methodological approaches used to assess these effects.

Although this thematic issue can cover only a small part of what has been done and can be done in the field of modelling and evaluating the sustainability of smart solutions, we hope that this collection of papers will stimulate research and, in particular, interdisciplinary cooperation in this field.

This Accepted Author Manuscript is copyrighted and published by Elsevier. The final publication is available at Elsevier via http://www.sciencedirect.com/science/article/pii/S1364815214001029

Suggested citation: Hilty, L.M., Aebischer, B., Rizzoli, A.E. 2014. Modeling and Evaluating the Sustainablity of Smart Solutions (Editorial), Environmental Modelling and Software 56, 1-5 


\section{References}

Fernàndez, C., Manyà, F., Mateu, C., Solé-Maur, F., 2014. Modelling Energy Consumption in Automated Vacuum Waste Collection Systems. Environmental Modelling and Software 56

Bohn, J., Coroama, V., Langheinrich, M., Mattern, F., Rohs, M., 2004. Living in a World of Smart Everyday Objects-Social, Economic, and Ethical Implications. Human and Ecological Risk Assessment 10 (4), 763-785.

Börjesson Rivera, M., Håkansson, C., Svenfelt, Å., Finnveden, G., 2014. Including second order effects in environmental assessments of ICT. Environmental Modelling and Software 56

Boulanger, P.-M., Couder, J., Marenne, Y., Nemoz, S., Vanhaverbeke, J., Verbruggen, A, Wallenborn, G., 2013. Household energy consumption and rebound effect HeCoRe. Belgian Science Policy D/2013/1191/1, Brussels

Caragliu, A., Del Bo, C., Nijkamp, P., 2009. Smart cities in Europe. Serie Research Memoranda 0048 (VU University Amsterdam, Faculty of Economics, Business Administration and Econometrics).

Clavreul, J., Baumeister, H., Christensen, T.H., Damgaard, A., 2014. EASETECH - an Environmental Assessment System for Environmental TECHnologies. Environmental Modelling and Software 56

Cook, D.J., Das, S.K., 2007. How smart are our environments? An updated look at the state of the art. Pervasive and Mobile Computing 3 (2), 53-73. http://dx.doi.org/10.1016/j.pmcj.2006.12.001.

Coroama, V.C., Hilty, L.M. 2014. Assessing Internet Energy Intensity: a Review of Methods and Results. Environmental Impact Assessment Review. 45 (2014) 63-68 DOI: 10.1016/j.eiar.2013.12.004

Coroama, V.; Hilty, L. M. 2009: Energy Consumed vs. Energy Saved by ICT - A Closer Look. In: Wohlgemuth, V., Page, B., Voigt, K. (Eds.): Environmental Informatics and Industrial Environmental Protection: Concepts, Methods and Tools, 23rd International Conference on Informatics for Environmental Protection, Berlin, 353-361

Coroama, V.C., Hilty, L.M., Heiri, E., Horn, F. 2013. The Direct Energy Demand of Internet Data Flows. Journal of Industrial Ecology 17 (5), 680-688 DOI: 10.1111/jiec.12048

Coroama, V.C., Hilty, L.M., Birtel, M., 2012. Effects of Internet-Based Multiple-Site Conferences on Greenhouse Gas Emissions. Telematics and Informatics 29, 362-374

EFC 2003. Energy Future Coalition, Smart Grid Working Group, 2003. Challenge and Opportunity: Charting a New Energy Future, Appendix A: Working Group Reports.

Erdmann, L., Hilty, L.M., Goodman, J., Arnfalk, P., 2004. The future impact of ICT on environmental sustainability. Synthesis Report. Institute for Prospective Technology Studies (IPTS), Sevilla

Erdmann, L., Hilty, L.M., 2010. Scenario Analysis: Exploring the Macroeconomic Impacts of Information and Communication Technologies on Greenhouse Gas Emissions. Journal of Industrial Ecology 14 (5), 826-843, DOI: 10.1111/j.1530-9290.2010.00277.x

Garrido-Baserba, M., Hospido, A., Reif, R., Molinos-Senante, M., Comas, J., Poch, M., 2014. Including the environmental criteria when selecting a wastewater treatment plant. Environmental Modelling and Software 56

GeSI. 2008. SMART 2020: Enabling the low carbon economy in the information age. The Climate Group on behalf of the Global eSustainability Initiative (GeSI)

GeSI. 2012. GeSI SMARTer 2020: The Role of ICT in Driving a Sustainable Future. Global eSustainability Initiative aisbl and The Boston Consulting Group, Inc.

Hilty, L.M., 2012: Why Energy Efficiency is not Sufficient: Some Remarks on "Green by IT". In: Arndt, H. K.; Pillmann, W. (eds.): EnviroInfo 2012, Proceedings of the 26th Environmental Informatics Conference, Shaker, Aachen, 13-20

Hilty, L.M., Lohmann, W., 2013. An Annotated Bibliography of Conceptual Frameworks in ICT for Sustainability. In: Hilty, L.M., Aebischer, B., Andersson, G., Lohmann, W. (Eds.). ICT4S 2013: Proceedings of the First International Conference on Information and Communication Technologies for Sustainability, Zurich, Switzerland, APPENDIX, 288-300. http://dx.doi.org/10.3929/ethz-a007337628

Hilty, L.M., Arnfalk, P., Erdmann, L., Goodman, J., Lehmann, M., Wäger, P., 2006a. The Relevance of Information and Communication Technologies for Environmental Sustainability - A Prospective Simulation Study. Environmental Modelling \& Software, 11 (21) 2006, 1618-1629, DOI: 10.1016/j.envsoft.2006.05.007

This Accepted Author Manuscript is copyrighted and published by Elsevier. The final publication is available at Elsevier via http://www.sciencedirect.com/science/article/pii/S1364815214001029

Suggested citation: Hilty, L.M., Aebischer, B., Rizzoli, A.E. 2014. Modeling and Evaluating the Sustainablity of Smart Solutions (Editorial), Environmental Modelling and Software 56, 1-5 
Hilty, L.M., Köhler, A., von Schéele, F., Zah, R., Ruddy, T., 2006b. Rebound Effects of Progress in Information Technology. Poiesis \& Praxis: International Journal of Technology Assessment and Ethics of Science, 1 (4), 19-38, DOI 10.1007/s10202-005-0011-2

Hilty, L.M., Aebischer, B., Andersson, G., Lohmann, W. (eds.). ICT4S 2013: Proceedings of the First International Conference on Information and Communication Technologies for Sustainability, Zurich, Switzerland. http://dx.doi.org/10.3929/ethz-a-007337628.

Hilty, L.M., Wäger, P., Lehmann, M., Hischier, R., Ruddy, T.F., Binswanger, M., 2004. The future impact of ICT on environmental sustainability. Fourth Interim Report. Refinement and quantification. Institute for Prospective Technological Studies (IPTS), Sevilla.

Hischier, R., Ahmadi Achachlouei, M., Hilty, L.M., 2014. Evaluating the Sustainability of Electronic Media: Strategies for Life Cycle Inventory Data Collection and their Im-plications for LCA Results. Environmental Modelling and Software 56

Kelly (Letcher), R.A., Jakeman, A.J., Barreteau, O., Borsuk, M.E., ElSawah, S., Hamilton, SH., Henriksen, H.J., Kuikka, S., Maier, H.R., Rizzoli, A.E., Van Delden, H., Voinov, A.A., 2013. Selecting among five common modelling approaches for integrated environmental assessment and management, Environmental Modelling \& Software, Volume 47, September 2013, Pages 159-181, ISSN 1364-8152, http://dx.doi.org/10.1016/j.envsoft.2013.05.005

Köhler, A.R., Hilty, L.M., Bakker, C., 2011. Prospective Impacts of Electronic Textiles on Recycling and Disposal. Journal of Industrial Ecology 15 (4), 496-511

Kolosz, B., Grant-Muller, S., Djemame, K., 2013. Modelling uncertainty in the sustainability of Intelligent Transport Systems for highways using probabilistic data fusion. Environmental Modelling \& Software 49 (2013) 78-97

Kramers, A., 2014. Designing next generation multimodal traveler information systems to support sustainability-oriented decisions. Environmental Modelling and Software 56

Kramers, A., Höjer, M., Lövehagen, N., Wangel, J., 2014. Smart Sustainable Cities - exploring ICT support of environmentally sustainable development in cities. Environmental Modelling and Software 56

Kräuchi, Ph.; Wäger, P.; Eugster, M.; Grossmann, G.; Hilty, L. M. 2005. End-of-life Impacts of Pervasive Computing. IEEE Technology and Society Magazine 24 (1), 45-53

Laitner, J.A., Koomey, J.G., Worrell, E., Gumerman, E. 2001. Re-estimating the Annual Energy 2000 Outlook Forecasting Using Updated Assumptions about the Information Economy. Washington, DC: Environmental Protection Agency / Berkeley, CA: Lawrence Berkeley National Laboratory.

Laitner, J.A., Knight, C.P., McKinney, V., Ehrhardt-Martinez, K., 2009. Semiconductor technologies: The potential to revolutionize U.S. energy productivity. Washington, DC: American Council for an Energy-Efficient Economy.

Laitner, J.A., 2010. Semiconductors and Information Technologies. The Power of Productivity. Journal of Industrial Ecology 14(5), 692-695. http://dx.doi.org/10.1111/j.1530-9290.2010.00284.X.

Laniak, G.F., Olchin, G., Goodall, J., Voinov, A.A., Hill, M., Glynn, P., Whelan, G., Geller, G., Quinn, N., Blind, M., Peckham, S., Reaney, S., Gaber, N., Kennedy, R., Hughes, A., 2013. Integrated environmental modeling: A vision and roadmap for the future. Environmental Modelling \& Software 39 (2013) 3-23

Lövehagen, N., Bondesson, A., 2013. Evaluating sustainability of using ICT solutions in smart cities methodology requirements. In: Hilty, L.M., Aebischer, B., Andersson, G., Lohmann, W. (Eds.), ICT4S 2013: Proceedings of the First International Conference on Information and Communication Technologies for Sustainability, Zurich, Switzerland, 184-191. http://dx.doi.org/10.3929/ethz-a007337628.

Mattern F., 2004. Ubiquitous Computing: Scenarios for an informatized world. In: Zerdick A., Picot A., Schrape K. (Eds), E-Merging Media, Springer, Berlin, 155-174.

Mickoleit, A., 2010. Greener and Smarter: ICTs, the Environment and Climate Change, OECD Green Growth Papers, No. 2010/01, OECD Publishing. DOI: 10.1787/5k9h3635kdbt-en

Niesse, A., Tröschel, M., Sonnenschein, M., 2014. Designing Dependable and Sustainable Smart Grids - How to Apply Algorithm Engineering to Distributed Control in Power Systems. Environmental Modelling and Software 56

OECD, 2011. Towards Green Growth: A summary for policy makers. OECD Meeting of the Council at Ministerial Level, 25-26 May 2011, Paris

This Accepted Author Manuscript is copyrighted and published by Elsevier. The final publication is available at Elsevier via http://www.sciencedirect.com/science/article/pii/S1364815214001029

Suggested citation: Hilty, L.M., Aebischer, B., Rizzoli, A.E. 2014. Modeling and Evaluating the Sustainablity of Smart Solutions (Editorial), Environmental Modelling and Software 56, 1-5 
Oertel, B.; Wölk, M.; Hilty, L. M.; Köhler, A.: Security Aspects and Prospective Applications of RFID Systems. Bundesamt für Sicherheit in der Informationstechnik, Bonn, 2005

Ruddy, T.F., Hilty, L.M., 2008. Impact Assessment and Policy Learning in the European Commission. Environmental Impact Assessment Review, 28 (2-3), 90-115

Shoukourian, H., Wilde, T., Auweter, A., Bode, A., 2014. Monitoring Power Data: a First Step Towards a Unified Energy Efficiency Evaluation Toolset for HPC Data Centers. Environmental Modelling and Software 56

Som, C., Hilty, L.M., Köhler, A.R., 2009. The Precautionary Principle as a Framework for a Sustainable Information Society. Journal of Business Ethics 85 (3), 493-505, DOI 10.1007/s10551009-0214-X

Som, C.; Hilty, L. M.; Ruddy, T. 2004: The Precautionary Principle in the Information Society. Human and Ecological Risk Assessment, 10 (5), 787-799

Stiel, F., Teuteberg, F., 2014. Measuring the Environmental Impact of IT/IS Solutions - A Life Cycle Impact Modelling Approach. Environmental Modelling and Software 56

Streicher-Porte, M.; Marthaler, C.; Böni, H.; Schluep, M.; Camacho, A.; Hilty, L.M. 2009. One Laptop per Child, Local Refurbishment or Overseas Donations? - Sustainability Assessment of Computer Supply Scenarios for Schools in Colombia. Journal of Environmental Management 90, 3498-3511

Wäger, P.; Eugster, M.; Hilty, L.M.; Som, C.: Smart Labels in Municipal Solid Waste - a Case for the Precautionary Principle? Environmental Impact Assessment Review 25 (5) 2005, 567-586

Weber, V., 2009. Smart Sensor Networks: Technologies and Applications for Green Growth. OECD Conference on "ICTs, the environment and climate change", Helsingør, Denmark, 27-28 May 2009, OECD Report DSTI/ICCP/IE(2009)4/FINAL

Welz, T., Hischier, R., Hilty L.M.,2011. Environmental impacts of lighting technologies — Life cycle assessment and sensitivity analysis. Environmental Impact Assessment Review 31 (3) 2011, 334343

Williams, D.R., Thomond, P., Mackenzie, I., 2014. The Greenhouse Gas Abatement Potential of Enterprise Cloud Computing. Environmental Modelling and Software 56

This Accepted Author Manuscript is copyrighted and published by Elsevier. The final publication is available at Elsevier via http://www.sciencedirect.com/science/article/pii/S1364815214001029

Suggested citation: Hilty, L.M., Aebischer, B., Rizzoli, A.E. 2014. Modeling and Evaluating the Sustainablity of Smart Solutions (Editorial), Environmental Modelling and Software 56, 1-5 